\title{
A Generic Framework of Performance Measurement in Networked Enterprises
}

\author{
Duk-Hyun $\mathrm{Kim}^{1}$ and Cheolhan $\mathrm{Kim}^{2}$ \\ ${ }^{1}$ Sejong Cyber University, 111-1 Gunja-dong, Gwangjin-gu, Seoul 143-150, Korea \\ dhkimesjcu.ac.kr \\ ${ }^{2}$ Daejon University, 96-3 Yongun-dong, Dong-gu, Daejon 300-716, Korea \\ chkimedju.ac.kr
}

\begin{abstract}
Performance measurement (PM) is essential for managing networked enterprises (NEs) because it greatly affects the effectiveness of collaboration among members of NE. PM in NE requires somewhat different approaches from PM in a single enterprise because of heterogeneity, dynamism, and complexity of NE's. This paper introduces a generic framework of PM in NE (we call it NEPM) based on the Balanced Scorecard (BSC) approach. In NEPM key performance indicators and cause-and-effect relationships among them are defined in a generic strategy map. NEPM could be applied to various types of NEs after specializing KPIs and relationships among them. Effectiveness of NEPM is shown through a case study of some Korean NEs.
\end{abstract}

Keywords: Performance Measurement, Networked Enterprise, Balanced Scorecard (BSC), Cause-and-Effect Relationships.

\section{Introduction}

Networked enterprise (NE) is an aggregation of private companies that work together for common goals; it is a kind of Collaborative-Networked Organization (CNO) [1]. Only to reduce the scope of our study we consider NE instead of CNO that includes non-profit organizations. NEs can be classified into three types: hub-and-spoke (e.g., extended enterprise with main contractor), supply chain (process-oriented), and peer-topeer (e.g., project-oriented virtual enterprise) [2]. Regarding the degree and direction of integration we call them vertical $N E$, horizontal $N E$, and ad-hoc $N E$, respectively. Three types of NEs have somewhat different characteristics in duration, goals, products or services, processes, ICT infrastructure, key performance indicators (KPIs), etc. For example, coordination mechanisms of vertical NE and ad-hoc NE are different, i.e., the former is close to command-and-control whereas the latter relies on debate or managerial/technical leadership. A generic framework for various types of NE could reduce efforts to implement management and ICT systems of NE.

Performance measurement (PM) is 'a systematic approach using methods and tools to plan, measure, monitor, assess, reward, and control the performance of processes and organizations' [3]. With PM an organization could be more goal-oriented, strategy focused, productive, and continuously improved. PM is essential for managing NEs because it greatly affects the effectiveness of collaboration among members. PM 
in NE requires somewhat different approaches from PM in a single enterprise because of heterogeneity, dynamism, and complexity of NE. Researches on PM in NE are relatively few yet compared to PM in Supply Chain Management (SCM) [5, 6, 7]. VOPM in ECOLAD [3, 4] touches PM in CNO; but, for now, it focuses on virtual organizations, i.e., ad-hoc NE, only.

This paper introduces a generic framework of PM in NE (we call it NEPM) based on the Balanced Scorecard (BSC) approach [8]. NEPM consists of 28 generic KPIs and cause-and-effect relationships (CAERs) among them, which makes a generic strategy map. The generic strategy map could be specialized into a specific strategy map of an NE, e.g., ad-hoc NE (type) or 'K-consortium' (instance), after selecting some KPIs and CAERs among them. Derivation of CAERs is often missed in previous researches based on BSC [5], which usually results in misalignment of business strategy and PM implementations or mismatch of enablers and results.

In Section 2 we review related work on PM in SCM and NE. Section 3 introduces basic features, i.e., KPIs and CAERs of NEPM. Section 4 explains a case study of applying NEPM to some Korean NEs and section 5 draws conclusion.

\section{Review of Related Work}

\subsection{Frameworks of Performance Measurement}

Lots of PM frameworks have been developed. Examples include Supply Chain Council Organization Reference (SCOR) model, BSC, economic value added, the European Foundation of Quality Management (EFQM) Excellence model, Supply Chain Event Management (SCEM), etc [3]. SCOR is effective for PM in an enterprise, but it does not yet provide sufficient measures for inter-enterprise collaboration and has no formal linkage between KPIs in different perspectives, e.g., finance and internal process [3]. BSC has been widely used for PM in profit and non-profit organizations because it helps keep balance between different forces in an organization, i.e., long-term vs. shortterm, internal vs. external, in-process vs. outcomes, and financial vs. non-financial measures. In this sense it categorizes KPIs into four perspectives: learning/growth, internal process, customer, and finance. A strategy map in BSC represents transformation of intangible assets (e.g., human capital, information and knowledge) into tangible assets including cash [8]. EFQM [9, 10] is one of Total Quality Management (TQM) frameworks. It consists of 9 criteria in 2 categories, i.e., leadership, people management, policy \& strategy, resources, and processes in enablers category; people satisfaction, customer satisfaction, impact on society, and business results in results category. SCEM [6] is a tool-based approach that focuses on visibility of entities that can be simply defined as 4-tuple, <entity, time, place, status>.

BSC and EFQM are more adequate for strategic-level PM, whereas SCOR and SCEM are more adequate for operational-level PM. EFQM has more generic constructs than BSC, SCOR, and SCEM because it aims at TQM of whole company rather than partial functions or processes. SCEM is an efficient and effective approach for visibility of some entities when mistrust among members exists [3]. Because it requires only a few metrics that could be accepted by most NE members. 


\subsection{Performance Indicators and Causal Relationships}

Performance measures or KPIs have been defined in most frameworks and by many researchers. For example, in SCOR 13 KPIs at strategy level and more than 200 KPIs at operational level are defined. In VOPM, KPIs are defined in 3 perspectives, i.e., finance, process, and collaboration [4], which means customer and learning/growth perspectives in BSC are omitted and collaboration is inserted instead. Gunasekaran et al. [7] suggest 46 metrics for SCM and classified them into SCOR processes (i.e., plan, source, make, deliver) and levels of management (i.e., strategic, tactical, operational). Bhagwat and Sharma [5] developed this framework and classified the metrics into 4 BSC perspectives. They stress the importance of building cause-and-effect relationships (CAERs) that enable managers to identify and control dependency between enablers and results. Matopoulos et al. [11] suggest a conceptual model for collaboration where they identify good indicators of collaboration, e.g., reduced inquiry time and inventory, increased quality and speed.

There have been many causal and factorial researches on interdependencies between enablers and results, but few findings are generally accepted yet. This is because it is not easy to formalize the semantics of interdependency that vary depending on viewpoints, focuses, and context of PM. Bou-Llusar et al. [9] review researches on CAERs among 9 criteria of EFQM. Examples of some meaningful findings are as follows.

- Leadership is the most important driver of system performance and affects financial results through systems element. Information and analysis is the second most important category (by Wilson and Collier).

- Information management, human resource management, and customer focus have significant effects on customer satisfaction and business results (by Pannirselvam and Schweikhart).

Besides EFQM, there have been some researches on interdependencies among performance measures. Most of them are not holistic but partial approaches that usually investigate the effects of several enabler variables to business results.

\section{A Framework of Performance Measurement}

\subsection{Overview of the Framework, NEPM}

NEPM is developed on the following rationale or assumptions.

- A PM framework helps create and design NEs, implement management/information systems, and share understanding of risk and benefit with all stakeholders.

- PM in NE should guarantee balance of different forces for all stakeholders of NE.

- In all types of NE, KPIs of collaboration among members are essential for NEPM.

Basic features of NEPM can be summarized, as follows.

- NEPM is a result of integrating ideas and constructs of BSC, EFQM, and SCEM.

- NEPM comprises of the following concepts:

(1) a set of generic KPIs in four perspectives of BSC;

(2) a generic strategy map with CAERs among the generic KPIs. 
- Generalization or specialization of NEPM could be accomplished by abstracting or augmenting KPIs and CAERs, which provides efficiency of design and execution of $\mathrm{PM}$ in NE to managers and practitioners.

\subsection{Generic Key Performance Indicators of NEPM}

Most of the generic KPIs of NEPM are developed on two previous frameworks: (1) the SCM metrics suggested by Gunasekaran et al. [7] and (2) the classification of those metrics into 4 BSC perspectives by Bhagwat and Sharma [5] (see the last column of Table 1). As the metrics of Gunasekaran's are result of theoretical and empirical analysis we adopt their key metrics to 28 KPIs of NEPM. However, because of some problems in the framework of Bhagwat and Sharma's we modify and extend it. One problem is that there is duplication of KPIs. For example, a KPI, i.e., 'buyersupplier partnership level' appears 3 times in finance, customer, and learning/growth

Table 1. KPIs and Some Features in the NEPM

\begin{tabular}{|c|c|c|c|c|}
\hline & KPIs in NEPM & $\begin{array}{l}\text { SCOR } \\
\text { proc. }\end{array}$ & $\begin{array}{l}\text { SCOR } \\
\text { level } 1\end{array}$ & Key Metrics for SCM \\
\hline$\overline{\mathrm{F} 1}$ & Procurement cost & source & cost & Buyer-supplier partnership \\
\hline $\mathrm{F} 2$ & Production cost & make & cost & Manufacturing cost \\
\hline F3 & Transportation cost & deliver & cost & Total transportation cost \\
\hline $\mathrm{F} 4$ & Marketing/sales cost & deliver & cost & Buyer-supplier partnership \\
\hline F5 & Customer service cost & deliver & $\operatorname{cost}$ & Customer query time \\
\hline F6 & Return on investment & plan & assets & Rate of return on investment \\
\hline F7 & Total inventory cost & plan & $\operatorname{cost}$ & Total inventory cost \\
\hline F8 & Total cash flow amount & plan & assets & Total cash flow time \\
\hline F9 & Information carrying cost & plan & cost & Information carrying cost \\
\hline $\mathrm{C} 1$ & Partner collaboration & plan & agility & Buyer-supplier partnership \\
\hline $\mathrm{C} 2$ & Product quality & make & resp. & Flexibility of service systems \\
\hline $\mathrm{C} 3$ & Delivery reliability & deliver & rel. & Delivery reliability \\
\hline $\mathrm{C} 4$ & Delivery lead time & deliver & resp. & Delivery lead time \\
\hline $\mathrm{C} 5$ & Customer response & deliver & resp. & Customer query time \\
\hline C6 & Information service & plan & agility & Information carrying cost \\
\hline $\mathrm{P} 1$ & Network cycle time & plan & agility & Total supply chain cycle time \\
\hline $\mathrm{P} 2$ & Accuracy of forecasting & plan & rel. & Accuracy of forecasting \\
\hline P3 & Product development cycle time & make & resp. & Product develop. cycle time \\
\hline $\mathrm{P} 4$ & Cash-to-cash cycle time & plan & assets & Total cash flow time \\
\hline $\mathrm{P5}$ & Total inventory amount & plan & assets & Total inventory cost \\
\hline P6 & Flexibility of service systems & plan & agility & Flexibility of service systems \\
\hline $\mathrm{P} 7$ & Capacity utilization & make & assets & Capacity utilization \\
\hline L1 & Leadership & plan & agility & Accuracy of forecasting \\
\hline $\mathrm{L} 2$ & Policy \& strategy & plan & resp. & Buyer-supplier partnership \\
\hline L3 & Human resources & plan & rel. & Product develop. cycle time \\
\hline L4 & $\begin{array}{c}\text { Other resources } \\
\text { (asset, finance, information) }\end{array}$ & plan & rel. & Capacity utilization \\
\hline L5 & Sourcing capability & source & resp. & Supplier ability to quality \\
\hline L6 & Delivery capability & deliver & resp. & Flexibility of service systems \\
\hline
\end{tabular}


perspectives. This, we believe, will make practitioners confusing when apply the framework. Another problem is that some KPIs in learning/growth perspective, e.g., 'product development cycle time' and 'capacity utilization', are not adequate for representing intangible asset of an organization according to BSC. For the problem of duplication we rename KPIs; and some KPIs are also renamed to have clear meaning according to BSC. For the problem of inadequate KPIs in learning/growth we adopt enablers in EFQM, e.g., leadership, human resources, etc. In addition, we try to extend the frameworks of a supply chain to a network of enterprises.

Table 1 shows the resultant KPIs of NEPM (see column 2) that consist of 9 KPIs in finance $(\mathrm{F} 1, . ., \mathrm{F} 9), 6$ in customer $(\mathrm{C} 1, . ., \mathrm{C} 6), 7$ in internal process $(\mathrm{P} 1$, .., $\mathrm{P} 7), 6$ in learning/growth (L1, .., L6). (Due to the limitation of space meaning of every KPI is omitted here.) The generic KPIs could be classified into 4 SCOR process types, i.e., plan, source, make, and deliver (see column 3). They could be classified into 5 categories of SCOR 'level 1 strategic metrics', i.e., reliability (rel), responsiveness (resp), agility, cost, and assets (see column 4).

\subsection{Generic Strategy Map of NEPM}

CAERs among the generic KPIs are not completely identified yet. So, we define them relying on few research results mentioned in section 2.2 and on some hypothesis. Empirical research need to be executed to further develop or augment the CAERs as well as the KPIs. Figure 1 shows the resultant generic strategy map.

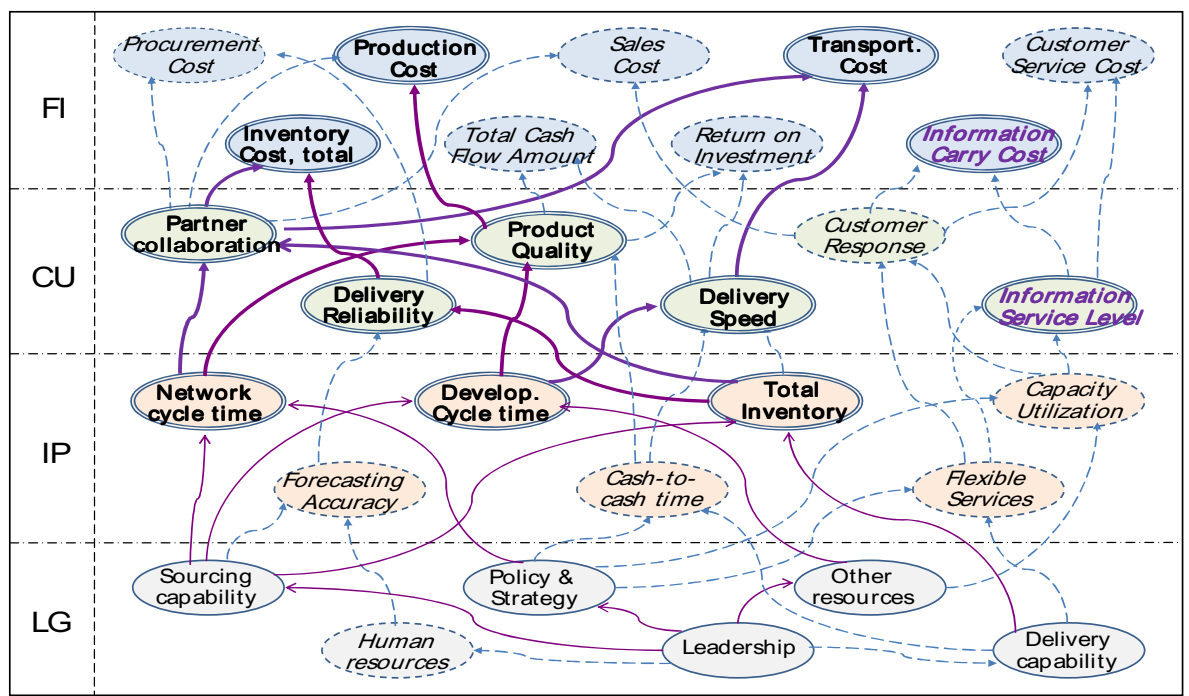

Fig. 1. The Generic Strategy Map \& A Strategy Map of K-consortium

Due to the limitation of space two concepts, i.e., the generic strategy map and a specific strategy map of a NE called K-consortium, are overlapped in the figure. In the figure you see the generic KPIs (ellipse) in 4 perspectives, i.e., learning/ growth 
(LG), internal process (IP), customer (CU), and finance (FI), and CAERs among them (curved lines). Other meanings will be explained in section 4 .

\section{An Illustrative Example}

For verification of NEPM we applied it to 10 Korean NEs. Some of them belong to vertical $N E$ of automotive and shipbuilding industry and the others belong to horizontal $N E$ of textile and electronics industry. They perform process innovation projects using RFID technology, partly sponsored by Korean government since 2006. Kconsortium belongs to automotive industry and consists of one vehicle maker as the leader, 4 suppliers of electronic/ mechanical/ optical parts, and one transportation company.

We obtained performance data for two years of execution from the final report of the project. K-consortium had less than $10 \mathrm{KPIs}$ when the project began. It, of course, doesn't have a strategy map, yet. So, it's hard to monitor and improve collaborative efforts and to calculate the effects of introducing new technology. Based on the costbenefit analysis K-consortium published we could identify its KPIs and implicit CAERs among them to draw a strategy map above. Note that it's a kind of reverse engineering to infer strategy and enablers from business results. If we are at planning stage of PM, after establishing vision and strategies, KPIs and CAERs are defined and then used to choose right resource allocation and courses of action.

In the strategy map 12 KPIs (double-lined ellipses) among 28 are identified in three perspectives (i.e., FI, CU, and IP) and CAERs among them (thick curved lines) also identified. Two KPIs, i.e., 'information carry cost' and 'information service' are identified, but CAERs that reach them are not identified, which means appropriate KPIs (say 'flexible services') are not measured, or some CAERs are missing or wrongly defined in the generic strategy map. In learning/growth perspective, 5 more KPIs (single-lined ellipse) and corresponding CAERs (thin curved lines) could be defined to allocate resources to appropriate actions at planning stage and could be identified to explain enablers (e.g., leadership, sourcing capability) of business results at evaluation stage.

Reviewing the results of applying NEPM to several Korean NEs we obtain many research questions that need to be investigated. Examples include: (1) relevance or relative importance of KPIs in each perspective, (2) definition of detailed metrics that will be actually measured for each KPI, (3) identification of more meaningful CAERs, (4) similarities and differences between different types of NEs, e.g., procurement-, engineering-, distribution-, and R\&D-focused NE as well as NEs with different properties (e.g., size, age, product or service).

\section{Conclusion}

In this paper, we suggest a generic framework of performance measurement in Networked Enterprises (NEPM) based on the Balanced Scorecard (BSC) approach. NEPM consists of a set of generic KPIs and cause-and-effect relationships (CAERs) among them to make a generic strategy map. It includes $28 \mathrm{KPIs}$ in four perspectives 
like BSC, i.e., learning/growth, internal process, customer, and finance. CAERs among the KPIs are identified on the basis of existing research, EFQM, and intuition of authors.

Although it may be a conceptual or theoretical model yet, NEPM has the following unique features: (1) the generic KPIs can provide network-centric view of PM to various stakeholders in NE, e.g., leading company, member company, supporting institutions, Virtual-organization Breeding Environment (VBE), etc; (2) NEPM considers total quality of management by adopting some constructs from EFQM such as 'leadership' and 'policy \& strategy'; and (3) CAERs among KPIs enable managers to align strategy and implementation effectively at both planning and evaluation stage.

Comparing with VOPM in ECOLEAD project our approach is somewhat different in the following points: (1) NEPM focuses on vertical NE and horizontal NE while VOPM on ad-hoc NE; (2) NEPM considers relatively long-lasting NEs including VBE while VOPM does short-lived or impermanent NEs; (3) the KPIs of NEPM are balanced in four perspectives while that of VOPM are classified into three perspectives, i.e., finance, process, and collaboration excluding customer and learning/growth in BSC.

Further research will include the following issues: empirical analysis of PM in various Korean NEs through interviews and surveys, theoretical research on the effects of enabler variables to result variables, comparative analysis between Korean and EU NEs, etc.

\section{References}

1. Camarinha-Matos, L.M., Afsarmanesh, H., Ferrada, F., Klen, A., Ermilova, E.: Rough Reference Model for Collaborative Networks. ECOLEAD Deliverables D52.2 (2006)

2. Katzy, B., Loeh, H.: Virtual Enterprise Research State of the Art and Ways Forward. CeTIM Working Paper (2003)

3. Graser, F., Westphal, I., Eschenbaecher, J. (eds.): Roadmap on VOPM Challenges on Operational and Strategic Level. ECOLEAD Deliverables 31.1 (2005)

4. Westfahl, I. (ed.): VOPM Approach, Performance Metrics, and Measurement Process. ECOLEAD Deliverables 31.2 (2005)

5. Bhagwat, R., Sharma, M.K.: Performance Measurement of Supply Chain Management: A Balanced Scorecard Approach. Computers \& Industrial Engineering 53, 43-62 (2007)

6. Francis, V.: Supply Chain Visibility: Lost in Translation? International J. of SCM 13(3), 180-184 (2008)

7. Gunasekaran, A., Patel, C., McGaughey, R.E.: A Framework for Supply Chain Performance Measurement. International J. of Production Economics 87, 333-347 (2004)

8. Kaplan, R.S., Norton, D.P.: The Strategy Map: Guide to Aligning Intangible Assets. Strategy \& Leadership 32(5), 10-17 (2004)

9. Bou-Llusar, J.C., Escrig-Tena, A.B., Roca-Puig, V., Beltran-Martin, I.: An Empirical Assessment of the EFQM Excellence Model: Evaluation as a TQM Framework Relative to the MBNQA Model. J. of Operations Management 27, 1-22 (2009)

10. Conti, T.A.: A History and Review of the European Quality Award Model. The TQM Magazine 19(2), 112-128 (2007)

11. Matopoulos, M., Vlachopoulou, M., Manthou, V.: A Conceptual Model for Supply Chain Collaboration: Empirical Evidence from the Agri-food Industry. International J. of SCM 12(3), 177-186 (2007) 